\title{
FEUERBACH E STIRNER: Algumas considerações sobre linguagem e política
}

\author{
Roberto Romano*
}

\section{TRANS/FORM/AÇÃO/25}

ROMANO, R. - Feuerbach e Stirner: algumas considerações sobre a linguagem e política. Trans/Form/Ação, São Paulo, 3:105-14, 1980.

RESUMO: "Habitualmente não se presta atenção ao fato de que a Primeira Parte da Ideologia Alemã ("Feuerbach"), foi a última a ser redigida por Marx. O texto, tal como nos aparece hoje, encobre portanto a gênese da crítica ao Humanismo. Esta última, como este pequeno ensaio pretende indicar, só poderia brotar do contacto meticuloso com o texto do Único e sua Propriedade. Após a leitura de Stirner, Marx pôde se acreditar liberado deste último fantasma especulativo e ideológico: o Homem."

UNITERMOS: Universalidade abstrata. Razão e Estado. Representação. Conceito e Visada. Inversão da dialética da SINNLICHE GEWISSHEIT. O Aqui e o Agora: progresso técnico e mudança radical da sociedade. A ideologia do MITTELSTAND.

"a Lógica tem (...) segundo $\mathrm{He}$ gel, a natureza inteira fora de si. A natureza começa para ele onde cessa o lógico. Por isso, para ele, a natureza em geral é ainda apenas a agonia do conceito"

(Schelling) **

Em artigo recente, o Prof. Gerard Lebrun (9) expõe de maneira clara as pressuposições universalizantes do pensamento progressista, novamente em vigor entre nós. O desfalecimento da crítica diante do genérico, a reiteração do tempo como continuidade inelutável, a retomada da educação popular como adestramento, são elementos que propiciam muita matéria à reflexão dos que ainda não dobraram-se à chantagem da "prática" e do "concreto", estes disfarces da Raison d'État, sob a marca registrada do revolucionarismo militante. De fato, nunca como agora a tese XI sobre Feuerbach, foi tão citada para garantir a misologia e para assegurar o domínio de uma certa interpretação do social, e seu consequiente controle da política.

Em nome do sacrossanto concreto, os intelectuais progressistas brasileiros, cujo discurso é o mais abstrato possível, arrogam-se a dignidade quase sacerdotal

* Professor Colaborador a nível de Assistente Doutor junto ao Departamento de Filosofia da Faculdade de Educação, Filosofia, Ciências Sociais e da Documentação da UNESP - Campus de Marília.

* Em 17, p. 332. 
ROMANO, R. - Feuerbach e Stirner: algumas considerações sobre linguagem e política. Trans/Form/Ação, São Paulo, 3:105-14, 1980.

de mediadores entre o Todo e o particular, levando (até hoje!) a "verdadeira consciência" às classes "em si", dandolhes a conhecer seu Destino real, colocando-as em seu lugar no espaço da nacionalidade. Intelectuais orgânicos auto-promovidos, os novos condutores da velha política científica refazem a interpretação do domínio ao interpretar os dominados. Nada há neste universo de representações que não seja uma retomada moderna da fala teológico-política, nada que não possa ser submetido à demolição espinosana dos fins e do milagre. Enquanto isto, eles próprios, sujeitos práticos, estão mergulhados até os ossos no objetivo final. A este leitor seria bom lembrar que a crítica da fantasmagoria racionalizante, vilipendiada pelo jovem Marx, longe de estar apartada da prática, constitui-se num dos seus elementos fundamentais. Sem ela, o mundo é de fato transformado, mas em que propriamente e em proveito de quem? $\AA$ falta de responder questões semelhantes *, as práticas só retomam as grandes certezas que são, na verdade as grandes ilusões cujo fim, e corolário, é substituir o rompimento efetivo com o status-quo pelo parco alimento das reformas e da comunidade das consciências, frutos do imaginário e do senso comum "como se não existisse nada mais infeliz do que um homem dominado por sua imaginação" $(14$, p. $7 ; 13$, p. 855$)$.

A obra feuerbachiana não pretendeu ser apenas mais uma crítica à religião cristã. Em todos os momentos buscou re- solver definitivamente o enigma religioso, a partir de sua intimidade. Mesmo para alguns contemporâneos, Feuerbach não foi considerado um simples anatomista do cristianismo, mas da própria religião em geral **. E, no juizo de Feuerbach sobre si mesmo, vemos não ter sido outro o objetivo de todo seu trabalho. Para ele, com efeito, a Essência do Cristianismo seria uma primeira elucidação radical do fenômeno religioso e cristão. (1, p. 348).

A imagem do anatomista no entanto, não dá conta de toda posição explícita de sua filosofia. $\mathrm{Na}$ realidade, e para utilizar ainda a linguagem médica corrente, ela buscou ser uma patologìa e uma terapêutica.

A tarefa de elucidar o verdadeiro fundamento, o real, atravessando as ilusões e fantasmas das representações humanas carentes de ciência, foi considerada como conditio sine qua non para a saíảa de alienação da qual os homens seriam produtos e produtores (19, p. 236).

Ser livre, neste sentido, seria ser liberto de um sistema englobante de justificação do mundo e dos homens: o cristianismo. E ser radicalmente livre, romper com os últimos resquícios de perversidade racionalizante, reunidos na filosofia absoluta de Hegel.

A cultura ocidental sofreria uma doença singular: nela, a liberdade individual estaria permanentemente em choque com a liberdade de todos os homens. A súmula desta contradição sentida e

* Na realidade, com a recusa de se refletir sobre o fundamento e as pressuposições da ação, terminou-se no pensamento progressista, por assumir a figura escolástica do Mestre, em cujos textos se encontraria a pura doutrina que "ao ser produzida já preconteria a virtude e os princípios de solução para 'resolver todos os problemas futuros' (...). Sorte extremada da modalidade 'vis a tergo', as injunções da ortodoxia marxista ombreiam neste particular com o tradicionalismo exacerbado ao estilo de De Bonald, De Maistre, Gustavo Corção" (15).

p. 88-89) "Feuerbach ist (...) der Anatom des Christenthums, der Religion überhaupt" (8, 
ROMANO, R. - Feuerbach e Stirner: algumas considerações sobre linguagem e política. Trans/Form/Ação, São Paulo, 3:105-14, 1980.

expressa como sentimento, seria o cristianismo. Pensada e exposta racibnalmente, o idealismo alemão. O tratamento dado às relações entre indivíduo e gênero mostra a ambiguiidade política da filosofia feuerbachiana: na Essência do Cristianis$m o$, o indivíduo foi considerado como uma ilusão, e, exatamente, o que emprestaria ao cristianismo o sentido de uma doença, é ser nele a individualidade vivida como absolutamente dobrada sobre si mesma, deleitando-se numa falsa existência, jogada numa existência falsa (2, p. 41, nota 3; p. 264 e 242).

O grande erro do idealismo seria justamente fundar-se neste $E u$ recebido acriticamente do espírito cristão, sem perceber que é apenas como relação que a egoidade pode possuir algum sentido racional (3, p. $185 ; 1, \mathrm{X}$, p. 189). Para assegurar um sentido à liberdade individual Feuerbach foi obrigado a pensar o gênero humano como um limite de harmonia e realização possível, dentro do qual ficaria assegurada, pela natureza comum, a coexistência de todos os homens $(3$, p. $165,166,167,168)$ *

Ora, o que ocorreria se mesmo esta totalidade limite fosse denunciada e compreendida como sobrevivência do próprio supersticioso e cristão?**

Postular um Todo, fundante em relação às partes, como único foco infinito de liberdade seria repor uma transcendência intolerável e abafante para a única existência efetiva: a particular. Tal é todo o sentido do Unico e sua Propriedade.
$\mathrm{O}$ erro de Feuerbach repercutiria no fracasso de sua crítica ao cristianismo. Feuerbach, aceitando o que este diz de si mesmo, não chegaria até o mais fundo na negação da transcendência cristã (o que seria imprescindível para sua supressão definitiva). Postular uma essência do gênero humano, acima e anteriormente à particularidade, seria reproduzir uma quebra entre o necessário (Gênero) e o insignificante (indivíduo). Seria por como ilusória justamente a atividade do indivíduo, abrindo novamente as portas para a contemplação, a teoria e a passividade. Em outros termos, matar a liberdade em sua fonte própria.

Caso contrário, como seria possível para Feuerbach criticar o cristianismo contemporâneo? E conhecido o itinerário da Essência do Cristianismo: o cristianismo atual, não sendo "clássico" não é "verdadeiro" (2, p. 14). Também a moral, a política, a ciência de seu tempo, seriam apenas "aparições" (2, p. 15) fantasmáticas, desprovidas de força essencial. Mas, porque Feuerbach necessitaria consagrar esta divisão entre o essencial e o aparente?

Por estar preso ao círculo da consciência idealista e cristã, esposando seu desdém pelo valor da particularidade. Detendo-se longamente sobre o Amor, representado por Feuerbach como uma potência que sobrepassaria e uniria os indivíduos no Gênero, Stirner mostra que, mesmo recoberto sob nomes laicos tais como "sociedade", "pátria", "bem público", etc, a afirmação do amor para além

* Cf. também 19, p. 267 "para o Feuerbach do segundo período, o gênero humano devia ser o horizonte de pensamento e de completude de todo homem individual e as mediações para alcançar o gênero humano eram as atividades da inteligência, da vontade, do amor".

* Responder positivamente a esta questão foi, como se sabe, o ponto de partida da filosofia política anarquista em seus primeiros choques ccm o pensamento liberal e, no limite, socialista. 
ROMANO, R. - Feuerbach e Stirner: algum as considerações sobre linguagem e política. Trans/Form/Ação, São Paulo, 3:105-14, 1980.

da fonte individual que lhe daria sentido é pura recaída e mascaramento de uma transcendência cuja expressão não é a liberdade real do indivíduo, mas pelo contrário, sua mais completa dominação: "as relações que fundam-se na Essência são relações com o fantasma, não com o real. Se me relaciono com o Ser Supremo, não é comigo que o $E u$ se relaciona e se me relaciono com o ser-do-Homem não me relaciono com o homem" $(18$, p. $327-$ 328) *

A falácia do amor universal mostraria todo seu peso político no ato mesmo da revolução: se o indivíduo aceitasse um instante sequer a existência de um ponto absoluto para além de si mesmo, aceitaria também imperceptivelmente toda uma carga de deveres, moral, religião, pouco importando o nome que portassem. $(18$, p. 335$)$.

Haveria um caminho direto entre a postulação da identidade metafísica do "real" e a impotência a que estaria condenado de antemão o indivíduo que nela acreditasse. Se minha fonte de identidade está fora de mim e me transcende, se, retirado dela, perco aquilo mesmo que me caracteriza essencialmente, se a liberdade somente tivesse sentido para $o$ infinito do Gênero, também sua realidade seria, para mim, adiada ao infinito. Ela seria mesmo, o fantasma dos fantasmas uma vez que "a liberdade não tem con- teúdo. Ela não tem valor, é permissão inútil, para quem não sabe empregá-la; quanto ao modo de emprego depende de minha particularidade" (18, p. 209)**

Ainda mais: a própria liberdade, se for determinada, será auto-negação. Sempre que se procura estar livre de alguma coisa, inadvertidamente, por exemplo, dar à seus defensores o nobre sentimento de que combatiam pela liberdade, em verdade foi apenas porque se visava uma liberdade determinada, logo uma nova $d o$ minação, a "soberania da Lei" (18, p. 213). A liberdade pois, é apenas um momento negativo, o qual perde todo sentido se for considerado em si e que se transforma em domínio se for determinado. A pergunta correta para Stirner, é aquela, sobre quem deve ser livre. A partir daí ter-se-á a indicação daquilo que ele deve ser. Ora, "Quem deve ser livre? Tu, Eu, Nós; e livres de que? De tudo aquilo que não é $\mathrm{Tu}, \mathrm{Eu}$, Nós. $\mathrm{Eu}$ sou pois, o núcleo, que deve ser liberado de todos os seus invólucros" $(18, \mathrm{p}$. 216).

Deste modo, uma vez chegados ao Eu livre, a liberdade entendida como um universal, perde todo o sentido, é apenas uma palavra, nada tendo a oferecer $(18$, p. 216). Ela só se realiza quando está ligada ao poder do $E u$. E a história real se funda não em "palavras vazias" $(18, \mathrm{p}$. 219) como a "liberdade dos povos" mas em individualidades vivas. $* * *$

* Também 18, p. 332: "deste modo o amor é, por essência razoável. É isto o que Feuerbach pensa, mas o crente, também pensa que é, e por essência igualmente-crente".

* * C. também 18, p. 214: "Por que não quereis ter a coragem de vos tomar, a vós mesmos, absolutamente como ponto central e objeto essencial? Por que quereis tolher a liberdade, vosso sonho? Não interrogueis de início vossos sonhos, vossas representações, vossas idéias, tudo isto é apenas "teoria vazia".

*** Cf. 18, p. 219: "Nero, u m imperador da China, um pobre escritor". Como em todo o Unico, este passo é muito claramente uma versão da astúcia da Razão e do papel da grande individualidade. Tanto pela recusa da determinação, quanto pelo papel fundante dado ao $\mathrm{Eu}$. Stirner estará atacando o raciocínio idealista presente nas filosofias de Feuerbach, Bruno, Bauer, Marx. Infelizmente não poderemos nos deter aqui neste ponto (cf. 6, p. 467 ). 
ROMANO, R. - Feuerbach e Stirner: algumas considerações sobre linguagem e polí. tica. Trans/Form/Ação, São Paulo, 3:105-14, 1980.

A liberdade do Todo é pois, uma palavra vazia. E o discurso de Feuerbach sobre ele, apenas uma transmutação de fantasmas. $\mathrm{O}$ cristianismo tem razão contra Feuerbach, ao desejar a liberdade do indivíduo: "Devemos, porque a liberdąde se revela como um ideal cristão, renunciar a ela? Não, nada deve ser perdido, nem a liberdade; mas ela deve tornar-se nossa, nosso bem próprio, o que ela não pode ser sob a forma de liberdade" (18).

Bem longe de realizar uma crítica ao cristianismo a partir do mascaramento que este faz da individualidade, Feuerbach está preso à maneira pela qual é posta pela religião cristã a relação entre o indivíduo e o mundo. Feuerbach é tão incapaz quanto o cristianismo de reconhecer o indivíduo, único e livre, a partir do instante em que o compreende como dependente do Gênero.

Feuerbach aceita a prosa moral cristã sem verificar o desvio que ela impõe à linguagem humana: o interesse pelo particular, entendido como "egoismo" a ser superado, partilharia da operação secreta pela qual a língua moderna se "conformou ao ponto de vista cristão" (18, p. 221).

Assim, a cultura moderna, longe de ser apenas uma aparência de cristianismo como postulava Feuerbach na Essência, é sua própria verdade, Feuerbach, crítico do cristianismo, é sua própria vítima e seu itinerário se fecha dentro dos limites impostos pela ideologia cristã. (18, p. $427 ; 19$ ).
O indivíduo livre e soberano só poderia se revelar ali onde termina radicalmente toda e qualquer distância entre o EU e o EU uma vez que "a consciência geral ainda é muito cristã para não ser tomada de medo e recuar diante de tudo o que não o é, como diante de algo imperfeito ou mau. Eis porque o "interesse pessoal tem tão péssima reputação" (18, p. 221).

Operar com a linguagem como se ela pudesse revelar imediatamente o real, sem atentar para a diversidade das significações que a atravessam é cair, necessariamente, no postulado de uma identidade do geral e do real. Mas a identidade, por exemplo, entre os interesses do indivíduo e os do Estado é mais do que problemática: é contraditória. Se a identidade fosse anterior a todo exercício particular da liberdade, a política mais exata seria a liberal. E que outra coisa é o liberalismo senão a última metamorfose da religião cristã? Ele é a "religião do Estado livre" (18, p. 226). Esta religião presta ao Estado o mesmo serviço que a piedade filial à família: "se esta última, com efeito, deve ser reconhecida e mantida em sua integridade por todos os seus membros é preciso que a ligação de sangue lhe seja sagrada e que ela seja honrada e respeitada como aquilo que torna cada parente sagrado a seus olhos. Do mesmo modo, a comunidade estatal deve ser sagrada para cada cidadão e a Idéia, que é para o Estado a Idéia suprema, deve sê-la também para ele" $(18$, p. 227).

A corrosão, pela filosofia de Stirner, da linguagem universalisante cristã e idealista * não deixou de causar consequên.

* "É apenas a partir do momento em que de Ti nada pode ser anunciado, em que tu podes ser apenas nomeado, que tu és reconhecido como Tu. Enquanto se enuncia alguma coisa de $\mathrm{Ti}$, tu és reconhecido apenas como alguma coisa (homem, espírito, cristão, etc.).O único nada enuncia porque ele é apenas um nome, ele nada mais faz do que dizer que Tu és $\Gamma u$, nada mais do que Tu, que Tu és um Tu único ou Tu mesmo. Então tu não tens predicado, e não tens ao mesmo tempo determinação, vocação, lei, etc." (18, p. 403). 
ROMANO, R. - Feuerbach e Stirner: algumas considerações sobre linguagem e política. Trans/Form/Ação, São Paulo, $3: 105-14,1980$.

cias na prosa feuerbachiana. Ela lhe serviu como um cadinho no trato das relações indivíduo-gênero. De tal modo que a figura do segundo vai perder, em textos posteriores à Essência do Cristianismo a anterioridade metafísica face aos indivíduos: ele será substituído pela natureza *, nova garantia contra a queda na armadilha do espírito teológico. Enquanto na Essência, o indivíduo era compreendido como ilusão, na obra posterior de Feuerbach se afirmará que só o indivíduo existe "não se podendo reificar" os predicados genéricos, pois caso contrário se recairia justamente na ilusão do espírito teológico" (20, p. 242-243; 1, VIII, p. 152ss; $1, \mathrm{X}$, p. 101). Natureza e sensibilidade passam a servir como operadores científicos verificáveis e visíveis e não mais como fundamentos meramente racionais de compreensão do mundo (11, p. 283ss, 16, p. 340).

Se a crítica do uso especulativo da noção de Gênero humano como essência levou Feuerbach a re-orientar sua compreensão da individualidade, ao mesmo tempo atacou irremediavelmente o liberalismo feuerbachiano e permitiu denunciar no Estado o portador de uma racionalidade cujo sentido seria a homogeinização das individualidades, acarretando seu acomodamento político $(18$, p. 376-377). Esta crítica ao caráter autoritário do Estado liberal passa pelo interior da crítica à filosofia especulativa, a qual, tanto quanto o Estado, teria como projeto a integração de todos os indivíduos sob si: "a especulação tinha por fim encontrar um predicado que fosse bastante geral pa- ra compreender cada indivíduo em sî" (18, p. 403).

Dominação política e justificação ideal não estão pois separados mas se constituem num movimento simultâneo de universalização e esfacelamento da particularidade, não havendo nenhuma razão para na crítica ao cristianismo, deixar subsistir qualquer pretensão à universalidade intocada, quer seja carregada pela política, pela religião ou pela moral.

Caberia perguntar sobre a possibilidade desta crítica radical de todas as representações positivas que se apresentam ao Unico: não são poucos os comentadores que apontam para um retorno do pensamento de Stirner à filosofia de Fichte ** no que seguem Marx e sua crítica do Unico na Ideologia Alemã ***. Embora não rejeitando o que haveria de verdadeiro neste "retorno", seria interessante notar a originalidade do modo pelo qual Stirner compreende sua tarefa de crítica filosófica, o que nos poderia ser útil na busca da compreensão das representações autoritárias aludidas no início deste artigo.

Certo, a auto-reflexão do Eu é o elemento fundamental da busca de Stirner, no sentido de uma liberdade radical. No entanto, está suposto, nesta sua maneira de experimentar o discurso sobre a liberdade, um rompimento absoluto com o discurso idealista, objetivo e subjetivo. Assim, suas diatribes também se dirigem contra o ideal da determinação

* A qual, no entanto, será negada o caráter de Ser universal, abstraída das "coisas reais, personificada e mistificada". (cf. 1, I, p. 410).

* * Entre outros, Lukacs (cf. 10, p. 212 e 238 ).

* * "É pois, apenas a manifestação de uma velha atitude de introspecção e de contrição cristã sob a forma germano-especulativa a atitude da fraseologia idealista, segundo a qual, não devo transformar a realidade, o que só posso fazer com os outros, mas transformar a mim mesmo, no fundo de mim mesmo" (12, p. 240). 
ROMANO, R. - Feuerbach e Stirner: algumas considerações sobre linguagem e política. Trans/Form/Ação, São Paulo, 3:105-14, 1980.

completa, de conexão sistemática dos elementos do saber. Stirner recusa justamente qualquer sistema perfeito e fechado em si mesmo, conforme a expressão do "Comunicado Claro como o Sol..." de Fichte $(5$, p. 79$)$.

"O que Stirner dỉz é uma palavra, uma idéia, um conceito; o que ele visa não é nem palavra, nem idéias nem conceito. $O$ que ele diz não corresponde àquilo que ele visa $\mathrm{e}$ aquilo que ele visa é indizível $(18, \mathrm{p}$. 400). A torsão operada na dialética da Sinnliche Gewissheit é notória: tomando o partido da visada, da opinião (Meinung) Stirner procura, não pela primeira vez na seqüência das críticas à filosofia absoluta, restaurar a dignidade do aqui e do agora, e denunciar o desvio lingüístico do "concreto" para o "abstrato". A subjetividade, longe de ser o ponto a ser determinado posteriormente pelas várias exposições prosaicas seria, pelo contrário, a fonte mesma da indeterminação e, como tal, da liberdade, no Ato e na Palavra.

Buscando uma "indeterminação completa" (18, p. 400-401) Stirner indica que justamente, a individualidade $a p a$ recia como o máximo de abstração na filosofia anterior, porque se tentava compreendê-la a partir daquilo que ela não é, ou seja, uma essência passível de ser fixada pelo Conceito e arramada às leis do Gênero $(18$, p. 401) .

Ora, o Unico é a presença da própria liberdade: nada daquilo que poderia ser deduzido a priori faz parte de seu conteúdo. Ou melhor: o único não é suscetível de nenhum conteúdo. Ele é: "a própria indeterminação" $(18$, p. 401$)$.

Esta liberdade em ato arrasta consigo uma reviravolta no plano das relações entre palavra e tempo: o ato de li- berdade não podendo ser retido conceitualmente, também não pode e não deve ser repetido posteriormente, o que poria em perigo a direção discursiva que na Fenomenologia do Espírito serviu como itinerário do Saber $(7$, p. 83$)$.

O novo ponto de partida de Stirner, pelo contrário, leva à negação do itinerário discursivo e da repetição: o conteúdo do Unico "não pode se repetir" $(18, \mathrm{p}$. 402) pois se ele pudesse ser repetido sabiamente, não mais estaria ele presente, mas apenas sua expressão discursiva e fantasmática (18, p. 401).

A aparição do Unico no discurso filosófico seria a última transmutação na ordem da palavra humana: ele é a Lógica que devora seus princípios $(18$, p. 404$)$ e no horizonte de Stirner, ele é um "enunciado que se transmuta em visada (Meinung)". É a própria ordem da Razão que deve ser subvertida, não a partir do exterior mas da denúncia de que a racionalidade $e ́$ superstição e fantasmagoria e sua exposição discursiva, frase morta, determinada, escrava *.

O Unico é uma tarefa provocadora: confrontados com ele o completamente desprovido de conteúdo, as grandes frases estouram do interior. Que significado teria para minha particularidade a marcha triunfal do Espírito na História, o interesse dos povos, da Pátria, do Partido? Se todas estas "realidades" ultrapassam o particular e não podem ser recolhidas por ele, não sendo sua "propriedade", é porque sua resistência é puramente formal. O predicado "homem" por exemplo, "não omite do sujeito sua subjetividade não dizendo quem, mas apenas aquilo que o sujeito é?" (18, p. 403).

Recolhidos os direitos do "agora" se compreende o porque da crítica de Stirner à separação feita por Feuerbach entre

* Para uma outra postura crítica quanto às relações entre "posição e exposição",(cf. 4, p. 58). 
ROMANO, R. - Feuerbach e Stirner: algumas considerações sobre linguagem e política. Trans/Form/Ação, São Paulo, 3:105-14, 1980.

o cristianismo autêntico, do passado, e o falso cristianismo do presente: Stirner acredita poder estourar com a pretensão do cristianismo atual (e seus continuadores laicos e ateus) à qualquer sentido: enquanto se puder mostrar que um determinado discurso se instala na distância do EU ao EU, ele é expressão residual de uma postura supersticiosa. $O$ salto entre o EU inicial e o EU final só poderia ser dado formalmente ou religiosamente, último caminho que, como se sabe, será o escolhido por Kierkegaard.

O Unico pretende ser pois a redução de todo discurso ao seu grau zero, à frase absolutamente desprovida de conteúdo. Colocando-se metódicamente no interior dos discursos com pretensões ao conteúdo, ele denunciará o resto universalizante que os assalta do interior. $\mathrm{O}$ Unico seria em "seu despojamento e nudez" a manifestação de que a maior frase é aquela que se dá como palavra saturada de sentido e conteúdo (18, p. 402). Deste modo, é tão desprovida de sentido a salvação oferecida pelo cristianismo, passado e contemporâneo, quanto qualquer manifestação piedosa sobre o Bem Comum, as tarefas espirituais do Estado, o progresso da civilização e da democracia: todas estas frases, na medida mesma em que encobrem a rejeição e o domínio da subjetividade são insignificantes. Aquele que as carrega consigo é doente de uma idéia fixa no sentido em que, de indeterminação mesma e fonte da liberdade, ele se torna colhido conceitualmente e fixado na Idéia, tornando-se apagado e impotente no interior de uma generalidade qualquer.

Após demasiado tempo de predomínio, no campo do saber auto-complacente do marxismo, de uma leitura dos jovens hegelianos como meros "idealistas pequeno-burgueses", parece importante retornar à reflexão sobre a crítica por eles instaurada. Não só porque ela é o solo comum compartilhado por Marx, mas porque alguns aspectos do processo de dominação que ela denuncia foram justamente assumidos pelos recitadores do Corão marxista.

É a partir da crítica dos pressupostos dos discursos autoritários, que se autoapresentam como redentores dos oprimidos que se manifesta a urgência de uma reflexão sobre a discordância entre a política que pregam, como se esta fosse expressão imediata do "real", e o sujeito a que se referem. Quando passamos pelo crivo da análise as entidades em que se apoiam, como por exemplo, o "povo", "as classes assalariadas", etc., temos sempre como resultado que o sujeito não manifesto, mas operante, é o Estado e seus partidos, e a liberdade alardeada é, finalmente, exclusiva propriedade destes agentes e não dos indivíduos e das classes efetivas.

Certo, a crítica do Capital pretende estourar o próprio princípio da propriedade, enquanto Stirner procura apontar para os truques de magia que transferem a propriedade para o Estado, para a Nação e não para os indivíduoos e classes efetivas dentro da sociedade capitalista. Mas, pergunta-se: qual discurso "marxista" ou materialista histórico de hoje, enuncia clara e distintamente a ruptura com toda propriedade privada? Se examinarmos os textos e programas dos realistas brasileiros (e mesmo europeus, etc.,) veremos que em nome da fatal etapa democrático. burguesa, única via possível para a passagem indolor para o socialismo, se "esquece" estes aspectos incômodos da filosofia marxista. Então, qual a diferença entre o jovem hegeliano pequeno burguês e os repetidores da letra do Capital?

Por mais que se possa mostrar a fraqueza e o abstrato da política anarquista de Stirner, o modo pelo qual ele critica as representações universalizantes postas em movimento pelo intelectual racionali- 
ROMANO, R. - Feuerbach e Stirner: algumas consideraçōes sobre linguagem e política. Trans/Form/Ação, São Paulo, 3:105-14, 1980.

zador do Estado moderno e burguês, pode se constituir em fonte heurística, dando ocasião para se indicar a inconsistência de discursos políticos que partem "ingenuamente" da missão civilizatória do Estado, e do progresso político que se seguiria necessariamente ao progresso econômico e social: o "bom" progresso, aquele que seria dirigido pelos "bons" intelectuais (orgânicos) é o supra-sumo da fantasmagoria.

Sobretudo, é preciso voltar-se contra a identificação metafísica entre progresso técnico e social e mudança radical da sociedade. O mito da técnica neutra, que permitiria o milagre de, por exemplo, colocar como libertador o processo de dominação mecânica da consciência, desde que esteja nas mãos dos ilustrados progressistas, tem junto a si a marca permanente da Instauratio Magna: domina-se a natureza como meio para se dominar os demais homens. Claro que como todo bom discurso ideológico, o dominador é o que se apresenta como fonte de libertação. A corrida dos progressistas (e da Igreja) aos meios de influência e comunicação de massa (TV, grande imprensa, cultura popular, etc) mostra bem que a mentalidade instrumental é o determinante dos novos libertadores.

Para terminar, apesar das ironias da Ideologia Alemã, à propósito do método stirneriano "para ver fantasmas", não encontramos ainda no 18 Brumário a recusa da repetição da política em história? $\mathrm{E}$ o que fariam os que ainda acreditam nas "lições do passado" das quais, habitualmente, livram-se por uma boa autocrítica sacramental, da denúncia de toda idéia fixa que pretenda colocar o passado como continuação tranquila no presente e no futuro?

$\mathrm{Na}$ obra de Marx, o "paraíso dos direitos humanos", o mundo do mercado e da sociedade civil não serão ainda postos como fetiche e fantasmagoria? Assim, há muito que meditar sobre as relações entretecidas pelo Único e sua propriedade e o Capital. A menos que os novos mediadores e guias da consciência, os propugnadores do ideal prosaico do Mittelstand, os intelectuais orgânicos, não tenham definitivamente entrado na dança do progresso e jogado os últimos resquícios da crítica marxista, com toda alegria e inocência prática na lata de lixo da História.

\section{TRANS/FORM/AÇÃO/25}

ROMANO, R. - Feuerbach and Stirner: some considerations on language and politics. Trans/Form/Ação, São Paulo, 3:105-14, 1980.

SUMMARY: Usually no attention is paid to the fact that the First Part of German Ideology ("Feuerbach") was the last one written by Marx. As it appears to us today the text therefore covers the genesis of the criticism of humanism. This criticism, as this short essay intends to point out, could only spring from a close contact with the text of The Unique and Its Property. After reading Stirner, Marx could believe himself freed from this last speculative and ideological ghost: Man.

UNITERMS : Abstract universality; reason and state; representation; Concept and Sight; inversion of the dialectics of Sinnliche Gewissheit; the Here and the Now: technical progress and radical change of society; the ideology of the Mittelstand. 
ROMANO. R. - Feuerbach e Stirner: algumas considerações sobre linguagem e política. Trans/Form/Ação, São Paulo, 3:105-14, 1980.

\section{REFERENCIAS BIBLIOGRÁFICAS}

1. FEUERBACH, L. Sämtliche Werke, X.

2 . Wesen des Christenthums. Stutgartt, Reclam.

3. Manifestes philosgrhiques. Trad. Althusser. Paris, PUF, 1963.

4. Crítica da filosofia de Hegel. Trad. ital. Lesa C., Bari, Laterza, 1972.

5. FICHTE. Comunicado claro como o Sol... Trad. Rubens R. Torres Filho. São Paulo, Abril, v. 2.

6. HEGEL, G.W.F. Enciclopédia das ciências filosóficas. Trad. francesa Gandillac. Paris, Gallimard, 1970.

7. pírito. Trad. francesa Hyppolite. Paris, 1939, v. 1.

8. KASSEL,J.C. Die Triarer, David Straus, Ludwig Feuerbach und Arnold Ruge und ihr Kampf für die Moderne Geistesfreiheit: Von einem Epigonem. J. Raccbé, 1852.

9. LEBRUN, Gerard. Artigo publicado na revista Manuscrito, Ano II, n. ${ }^{\circ}$ II. Departamento de Filosofia de Campinas, Unicamp.

10. LUKACS, G. $O$ assalto à razão. Trad. Roces, W. México, Grijalho, 1967.
11. MARCUSE, H. Vermunft und Revolution. Berlin, Neuwied, 1962.

12. MARX, K. Ideologia alemã. Trad. Badia. Paris, Ed. Sociales, 1960.

13. PASCAL. Pensús, frag. 106. Pleíade.

14. PLINIO. Livro II, Belles Lèttres.

15. PUPPI, Ubaldo. $\mathrm{O}$ auto-questionamento da Filosofia. Comunicação à IV Jornada de Filosofia, Marília UNESP, 1979. Publicada neste número de Transformação.

16. RAWDOWIEZ, Ludwig. Fennerbach's Philosophie - Ursprung und Sehicksal. Berlin, Vertg Renthen \& Reichard, 1931.

17. SCHELLING. História da filosofia moderna: Hegel. Trad. Rubens R. Torres Filho. São Paulo, Abril, 1973.

18. STIRNER, $O$ único e sua propriedade: Oeuvres complètes. Trad. francesa de Gallisaire.

19. Respostas a Feuerbach, Szeliga, Hess. In: Oeuvres complètes. Trad. francesa de Gallisaire.

20. XHAUFFLAIRE. Feuerbach et la théologie de la sécularisation. Paris, Du Cerf. 1970. 